\title{
ESTUDO DE DIFERENTES EXTRATOS NA ELABORAÇÃO DE FILME BIODEGRADAVEL A PARTIR DE FARINHA DE FRUTAS E HORTALIÇAS
}

\author{
N.V.BRUNO ${ }^{1}$; FAI, A.E.C. ${ }^{1,2}$; SOUZA, M.R.A. ${ }^{1}$; GONÇALVES, E C B A ${ }^{1,2}$ \\ ${ }^{1}$ Departamento de Tecnologia de Alimentos, Escola de Nutrição, Universidade Federal do Estado do Rio de \\ Janeiro, Brasil \\ 2 Programa de Pós-graduação de Alimentos e Nutrição, Universidade Federal do Estado do Rio de Janeiro, \\ Brasil \\ E-mail para contato: ediracba@analisedealimentos.com.br
}

\section{RESUMO:}

O desenvolvimento de filmes biodegradáveis merece atenção devido ao crescente impacto ambiental causado por embalagens plásticas. Verifica-se um número considerável de estudos utilizando frutas e hortaliças na elaboração de plásticos degradáveis, mas poucos utilizam resíduos industriais para esse fim. Este estudo verificou o potencial de produção de filmes biodegradáveis à base de resíduo, transformado em farinha, do processamento integral de frutas e hortaliças. Foram elaborados filmes através da técnica casting a partir da solução extraída do resíduo citado em meio alcalino e alta temperatura. Foi observado que a extração da farinha de frutas e hortaliças com tampão pH 9, composto de hidróxido de amônio e ácido ortofosfórico, atribui ao filme formado maior espessura e melhores características mecânicas, quando comparado aos demais avaliados, apresentando tensão na ruptura, elongação na ruptura e módulo Young de 0,2522 \pm 0,0126, 14,6800 $\pm 4,1175$ e $0,1822 \pm 0,0472$, respectivamente. Este estudo segue em andamento visando melhorar as propriedades mecânicas dos filmes e otimizar este processo.

\section{INTRODUÇÃO}

O desenvolvimento de filmes biodegradáveis tem merecido atenção intensa dos pesquisadores devido ao crescente impacto ambiental causado por embalagens plásticas (PELIZER et al., 2007; FRANCHETTI \& MARCONATO, 2006).

Até pouco tempo atrás era importante descobrir materiais cada vez mais resistentes e duráveis para utilização diária no mercado e dentre estes estavam os plásticos, com grande variedade de aplicações, devido a suas propriedades, versatilidade de uso e preço acessível. A utilização de embalagens plásticas cresceu em larga escala nas ultimas décadas e, como consequência, o descarte deste material tornou-se cada vez mais frequente em todo o mundo. Além de serem produzidos a partir de uma matéria-prima não renovável (o petróleo) os materiais plásticos são muito resistentes à degradação natural, tornando-se este um problema de acúmulo de resíduo de natureza global. Sabe- 
se, por exemplo, que muitos plásticos exigem mais de 100 anos para degradação total, uma vez que sua alta massa molar média e hidrofobicidade dificultam a ação dos microrganismos e de suas enzimas na superfície do polímero (FRANCHETTI \& MARCONATO, 2006; GORNI, 2006).

$\mathrm{Na}$ tentativa de minimizar esta problemática, os avanços tecnológicos lograram a obtenção de filmes biodegradáveis produzidos com materiais oriundos de fontes renováveis e não poluentes, sendo os resíduos agroindustriais as fontes preferidas de matéria-prima para estes filmes (FRANCHETTI \& MARCONATO, 2006; GUILBERT \& GONTARD, 2005).

Nesse contexto, os assim denominados plásticos ambientalmente degradáveis trazem em seu bojo uma opção adicional de gerenciamento de resíduos, tais como aqueles gerados na industrialização de produtos de horticultura. A degradabilidade desses materiais, após seu uso permite que eles permaneçam no ciclo natural do carbono (INNOCENTNI-MEI e MARIANI, 2005).

Apesar de alguns pesquisadores terem relatado a utilização de frutas e hortaliças como matéria-prima para a para elaboração de embalagens biodegradáveis (AZEREDO et al., 2012; DU et al., 2011; MARTELLI et al., 2011) poucos trabalhos associam o uso de resíduos orgânicos como talos, cascas e sementes como fontes alternativas para este fim (BARBOSA et al., 2011; OOI et al., 2012; PARK \& ZHAO, 2006).

Para o agronegócio brasileiro, o uso de embalagens biodegradáveis fabricados com resíduos oriundos do processamento de frutas e hortaliças, apresenta um enorme potencial de aplicações e a utilização destes subprodutos com esta vertente mostra-se muito promissora. Esse uso está relacionado à presença de polissacarídeos em sua composição, como pectina, amido, e derivados de celulose, que apresentam capacidade filmogênica, formando matrizes coesas com uma variedade de açúcares, que podem atuar como plastificantes naturais (MARTELLI et al., 2011). Este estudo visou a produção de filmes biodegradáveis pelo processo de casting, a partir da farinha de frutas e hortaliças (FFH), utilizando diferentes extratos.

\section{METODOLOGIA}

\subsection{Fabricação da farinha de resíduos de frutas e hortaliças (FFH)}

A FFH foi produzida segundo método estabelecido por Ferreira et al. 2013. As frutas e utilizadas foram: laranja seleta (Citrus sinensis), maracujá (Passiflora edulis) e melancia (Citrullus lanatus). As hortaliças utilizadas foram: abobrinha (Cucúrbita pepo), alface (Lactuca sativa), cenoura (Daucus carota), espinafre (Spinacea oleracea), hortelã (Mentha s.p.), inhame (Colocasia esculenta), pepino (Cucumis sativus) e rúcula (Eruca sativa). Todas as amostras foram adquiridas em um supermercado no bairro de Botafogo, Rio de Janeiro, e transportadas ao laboratório para uso imediato.

\subsection{Elaboração de filmes biodegradáveis}


A FFH foi utilizada como substituto de polissacarídeos para a fabricação de filmes biodegradáveis. Os filmes biodegradáveis foram formulados a partir de FFH como base da solução filmogênica.

A solução filmogênica foi obtida mediante a extração da FFH em diversos extratores, em altas temperaturas e com agitação constante. Para obtenção de uma solução filmogênica homogênea, as soluções foram peneiradas, filtradas em poliéster e então centrifugadas. Os filmes biodegradáveis foram preparados segundo a técnica do tipo casting ou dispersão/espalhamento: as soluções filmogênicas foram dispersas em placas de acrílico $(14,5$ x 14,5 cm) e secas em estufa com circulação e renovação de ar.

Foram utilizados como extratores água e soluções tampões com pH 7 e 9 (I), compostos de hidróxido de amônio e ácido metafosfórico, e pH 9 (II) composto de hidróxido de amônio e ácido ortofosfórico. Os filmes elaborados foram pré-acondicionados $\left(57 \% \mathrm{UR}, 25^{\circ} \mathrm{C}\right)$ por 5 dias e foram então analisados.

\subsection{Análises para avaliação dos filmes produzidos}

\section{$\underline{\text { Espessura }}$}

A espessura dos biofilmes foi determinada utilizando-se um micrômetro digital $( \pm 0,001 \mathrm{~mm})$ (Mitutoyo, Suzano, Brazil),com sensor de medida de 6,4 $\mathrm{mm}$ de diâmetro, em três pontos diferentes, considerando-se a espessura do filme como a média entre as três leituras.

\section{Propriedades mecânicas dos filmes}

As propriedades mecânicas foram determinadas através de testes de tração (tensão na ruptura, elongação na ruptura e módulo Young) utilizando-se um texturômetro TMS/Pro (Food Technology Corporation, EUA) de acordo com o método ASTM D882 (ASTM, 1995). As amostras foram submetidas a tração com velocidade de $1 \mathrm{~mm} / \mathrm{s}$. Os valores apresentados como resultados representam a média entre 7 e 10 aferições para cada amostra.

\section{Tratamento estatístico}

Os resultados obtidos foram analisados pelo teste de Tukey a nível de 5\% de significância utilizando-se o programa ASSISTAT versão 7.7 beta.

\section{RESULTADOS E DISCUSSÃO}

A farinha de resíduos de frutas e hortaliças produzida e avaliada neste estudo demonstrou-se como um promissor material multicomposto para a produção de filmes biodegradáveis. Os filmes obtidos a partir de extração com as soluções tampão apresentaram espessura homogênea com a superfície lisa sem rugosidades, cor amarelada e com boa manuseabilidade (Figura 1). 


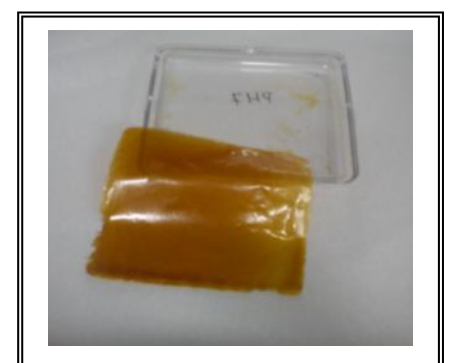

Figura 1 - Filme elaborado a partir da extração com tampão 7 (ácido metafosfórico e hidróxido de amônio) de $8 \%$ da FFH.

Os filmes apresentaram espessura média variando de $0,1530 \mathrm{~mm} \pm 0,0350$ a $0,2306 \pm 0,004$, com diferença significativa entre si (Tabela 1), evidenciando que a extração de compostos capazes de formar filmes mais espessos está diretamente correlacionada com o extrator aplicado.

Tabela 1 - Média de espessura dos distintos filmes obtidos a partir da extração de $8 \%$ da FFH.

\begin{tabular}{cc}
\hline Extrator & $\begin{array}{c}\text { Espessura do filme } \\
\text { formado }(\mathbf{m m})\end{array}$ \\
\hline Água & $0,1530 \mathrm{~b} \pm 0,0350$ \\
Tampão pH 7,0 & $0,1960 \mathrm{ab} \pm 0,0017$ \\
Tampão pH 9, 0 (I) & $0,2146 \mathrm{a} \pm 0,0015$ \\
Tampão pH 9, 0 (II) & $0,2306 \mathrm{a} \pm 0,0040$
\end{tabular}

Resultados expressos como média \pm desvio padrão $(\mathrm{n}=3)$. Médias seguidas pela mesma letra não diferem estatisticamente pelo Teste de Tukey ao nível de 5\% de probabilidade.

As médias de espessura evidenciadas neste estudo foram superiores às relatadas por Souza, Silva \& Druzian (2012) em estudo comparativo de filmes biodegradáveis de amido de mandioca contendo polpas de manga e de acerola, cujos filmes variaram $0,123 \mathrm{~mm}$ e $0,140 \mathrm{~mm}$, como também por Almeida et al. (2013) que observaram, médias de espessura entre 0,020 mm a 0,078mm para filmes compostos por blenda fécula de batata e celulose bacteriana.

De acordo com Andrade (2013) a concentração das matérias-primas utilizadas pode interferir na espessura dos filmes formados, pois soluções mais viscosas tendem a formar filmes mais espessos. Neste estudo, observou-se que as extrações com soluções tampão geraram soluções filmogênicas visualmente mais viscosas; a espessura dos filmes extraídos com $\mathrm{pH} 9$ foi 
estatisticamente maior quando comparada ao filme oriundo da extração aquosa. Com isto, e pelo fato do filme obtido com solução aquosa apresentar dificuldades em relação à sua manuseabilidade, decidiu-se não prosseguir os estudos das propriedades mecânicas com este.

Filmes com propriedades mecânicas ideais devem ser resistentes à ruptura e abrasão, para proteger os produtos nos quais são aplicados, e flexíveis, de forma que possam se adaptar a possíveis deformações e resistirem à fratura (ANDRADE, 2013). As respostas aos testes de propriedades mecânicas avaliadas neste estudo estão descritas na Tabela 2.

Tabela 2 - Média das propriedades mecânicas dos distintos filmes obtidos a partir da extração de $8 \%$ da FFH.

\begin{tabular}{lccc}
\hline \multicolumn{1}{c}{ Extrator } & $\begin{array}{c}\text { Tensão na ruptura } \\
(\mathbf{M P a})\end{array}$ & $\begin{array}{c}\text { Elongação na } \\
\text { ruptura (E\%) }\end{array}$ & $\begin{array}{c}\text { Módulo de Young } \\
(\mathbf{M P a})\end{array}$ \\
\hline $\begin{array}{l}\text { Tampão pH 7,0 (com ácido } \\
\text { metafosfórico) }\end{array}$ & $0,1345 \mathrm{~b} \pm 0,0011$ & $17,4400 \mathrm{a} \pm 1,7440$ & $0,0778 \mathrm{~b} \pm 0,0033$ \\
$\begin{array}{l}\text { Tampão pH 9, 0 (com ácido } \\
\text { metafosfórico) }\end{array}$ & $0,0037 \mathrm{c} \pm 0,0006$ & $10,7600 \mathrm{~b} \pm 2,5187$ & $0,02958 \mathrm{c} \pm 0,0055$ \\
$\begin{array}{l}\text { Tampão pH 9, 0 (com ácido } \\
\text { ortofosfórico) }\end{array}$ & $0,2522 \mathrm{a} \pm 0,0126$ & $13,0600 \mathrm{~b} \pm 2,272$ & $0,1822 \mathrm{a} \pm 0,0472$ \\
\hline
\end{tabular}

Resultados expressos como média \pm desvio padrão $(n=3)$. Médias seguidas pela mesma letra não diferem estatisticamente pelo Teste de Tukey ao nível de 5\% de probabilidade.

As propriedades mecânicas de tração são úteis para a identificação e caracterização de filmes, pois expressam a resistência do material ao alongamento e ao rompimento quando submetido à tração (RODRIGUES, 2012). Os filmes devem ter uma resistência mecânica suficiente para garantir a integridade dos mesmos quando utilizados como embalagem (ZAVAREZE et al., 2012).

De acordo com Davanço, Tanada-Palmu \& Grosso (2007) as propriedades mecânicas dos filmes são dependentes das interações entre os componentes, ou seja, da formação de fortes ligações moleculares e/ou numerosas entre as cadeias.

Neste trabalho, observou-se que o filme oriundo da extração da FFH com solução tampão de $\mathrm{pH}$ composto de hidróxido de amôio e ácido ortofosfórico apresentou tensão na ruptura de 0,2522 $\mathrm{MPa} \pm 0,0126$ sendo estatisticamente maior que a resitência dos demais filmes. Acredita-se que esta solução foi mais eficaz na extração de compostos presentes na FFH capazes de formar uma matriz polimérica mais coesa através de interações químicas mais fortes, resultando em um filme com melhor performance no teste de tensão à ruptura.

Observa-se que este mesmo filme apresentou também o maior valor para o módulo de Young, diferindo estatisticamente dos demais filmes. O módulo de Young ou módulo de elasticidade é um indicador da rigidez dos filmes, logo, quanto maior o valor do módulo de Young, maior a rigidez do material (ANDRADE, 2013).

Percebe-se através dos resultados obtidos, que a diminuição do pH favoreceu a elevação da elongação na ruptura dos filmes. Isto provavelmente se deve à capacidade do tampão pH 7 , constituído de hidróxido de amônio e ácido metafosfórico, em reduzir as interações entre cadeias poliméricas, decrescendo a resistência do filme e aumentando a capacidade de elongação do mesmo. Em ouras palavras, o tampão pH 7 aumentou a extensibilidade do filme produzido e reduziu a sua força mecânica. 
Estudos têm indicado que os vegetais e seus resíduos são matérias-primas promissoras para a elaboração de filmes biodegradáveis, sendo oriundos de fontes renováveis e não tóxicos para o solo e para o ambiente. Tal uso está relacionado à presença de polissacarídeos em sua composição, como pectina, amido, e derivados de celulose, que apresentam capacidade filmogênica, formando matrizes coesas com uma variedade de açúcares, que podem atuar como plastificantes naturais (ANDRADE, 2013; AZEREDO et al., 2012). A Tabela 3 apresenta a comparação do filme obtido da extração com tampão pH 9,0 (ácido ortofosfórico), considerado o mais resistente deste estudo, com filmes oriundos de produtos e subprodutos vegetais, relatados na literatura.

Percebe-se que os filmes elaborados, a partir do resíduo de frutas e hortaliças, apresentados nesta pesquisa, apresentam um relevante potencial como matéria-prima para produção de filmes. A obtenção dessses filmes biodegradáveis a partir de resíduos agroindustriais é considerada ainda uma excelente estratégia de agregar valor a estes subprodutos descartados em grande volume pela indústria de alimentos apresentando, dessa forma, benefício ambiental de duplo impacto.

Tabela 3- Compação das médias máximas de propriedades mecânicas de filmes elaborados a base de produtos e subprodutos vegetais.

\begin{tabular}{|c|c|c|c|c|}
\hline Material do filme & $\begin{array}{c}\text { Tensão na } \\
\text { ruptura (MPa) }\end{array}$ & $\begin{array}{c}\text { Elongação na } \\
\text { ruptura }(\%)\end{array}$ & $\begin{array}{c}\text { Módulo de Young } \\
(\mathrm{MPa})\end{array}$ & Referência \\
\hline $\begin{array}{l}\text { Filme multicomposto de } \\
\text { resíduos vegetais de frutas } \\
\text { e hortaliças sem aditivos. }\end{array}$ & $0,2522 \pm 0,0126$ & $13,0600 \mathrm{~b} \pm 2,272$ & $0,1822 \pm 0,0472$ & Este estudo \\
\hline $\begin{array}{l}\text { Filme multicomposto de } \\
\text { resíduos vegetais } \\
\text { acrescido de farinha de } \\
\text { batata }\end{array}$ & $0,0840 \pm 0,0210$ & $34,4900 \pm 5,1100$ & $0,0040 \pm 0,0001$ & Andrade, 2013 \\
\hline $\begin{array}{l}\text { Filme de purê Banana } \\
\text { adicionado de glicerol }\end{array}$ & $3,2000 \pm 0,5000$ & $24,0000 \pm 3,000$ & $21,0000 \pm 3,0000$ & $\begin{array}{c}\text { Martelli, Barros \& } \\
\text { Assis, } 2014\end{array}$ \\
\hline $\begin{array}{l}\text { Filme de purê de maçã } \\
\text { contendo óleos essenciais }\end{array}$ & $0,6400 \pm 0,0100$ & $25,4000 \pm 2,1000$ & $5,0600 \pm 0,5400$ & $\begin{array}{c}\text { Rojas-Grau et al., } \\
2006\end{array}$ \\
\hline $\begin{array}{l}\text { Filme de amido } \\
\text { adiconado de acerola }\end{array}$ & $3,9720 *$ & $44,6300^{*}$ & - & Farias et al., 2011 \\
\hline $\begin{array}{l}\text { Filme de purê de manga } \\
\text { reforça com nanofibras de } \\
\text { celulose }\end{array}$ & $8,7600 \pm 0,1100$ & $43,3000 \pm 1,4600$ & $322,0500 \pm 19,4300$ & $\begin{array}{l}\text { Azeredo et al., } \\
2009\end{array}$ \\
\hline $\begin{array}{l}\text { Filme de bagaço de } \\
\text { cranberry adicionado de } \\
\text { pectina e glicerol }\end{array}$ & $8,1000 \pm 1,9000$ & $39,0000 \pm 3,200$ & - & $\begin{array}{l}\text { Park \& Zhao, } \\
2006\end{array}$ \\
\hline
\end{tabular}

* Desvio padrão não informado pelos autores. 
Comparando os parâmetros de tração dos filmes apresentados na Tabela 3, percebe-se que os filmes produzidos neste estudo ainda são frágeis em relação às suas propriedades mecânicas. Contudo, ressalta-se que estes não são adicionados de aditivos que reforcem suas propriedades de tração, ao contrário da maior parte dos demais.

\section{CONCLUSÃO}

A farinha de frutas e hortaliças avaliada neste estudo demonstrou um potencial interessante de utilização como um material multicomposto alternativo para produzir filmes biodegradáveis. Foi observado que a extração da FFH com tampão $\mathrm{pH}$ 9, composto de hidróxido de amônio e ácido ortofosfórico, atribui ao filme maior espessura e melhores características mecânicas relacionadas à tensão na ruptura e elasticidade, diferindo estatisticamente dos demais filmes produzidos. O filme derivado da extração com tampão $\mathrm{pH}$ 7,0 apresentou maior valor para a propriedade de elongação na ruptura. Assim, este estudo segue em andamento visando melhorar as propriedades mecânicas dos filmes.

\section{REFERÊNCIAS BIBLIOGRÁFICAS}

ALMEIDA, D.M.; WOICIECHOWSKI, A.L.; WOSIACKI, G.; PRESTES, R.A.; PINHEIRO, L.A. Propriedades Físicas, Químicas e de Barreira em Filme Formados por Blenda de Celulose Bacteriana e Fécula de Batata. Polímeros, v.23, n.4, p. 538-546, 2013.

AMERICAN SOCIETY FOR TESTING AND MATERIALS (ASTM). Standard test methods for tensile properties of thin plastic sheeting (D 882-95). In: Annual Book of ASTM Standards. Philadelphia, PA, 1995.

ANDRADE, R.M.S. (2013). Desenvolvimento e caracterização de filmes biodegradáveis à base de resíduos de frutas e hortaliças. 2013. 70p. Dissertação (Mestrado em Alimentos e Nutrição) Universidade Federal do Estado do Rio de Janeiro.

AZEREDO, H. M. C.; MATTOSO, L. H. C.; WOOD, D.; WILliAMS, T. G.; AVENABUSTILlOS, R. J.; MCHUGH, T. H. Nanocomposite edible films from mango puree reinforced with cellulose nanofibers. Journal of Food Science, v. 74, n. 5, p. 31-35, 2009.

AZEREDO, H. M. C,; MIRANDA, K. W. E.; ROSA. M. F.; NASCIMENTO, D. M.; MORA, M. R. Edible films from alginate-acerola puree reinforced with cellulose whiskers. LWT-Food Science and Technology, v.46, p.294-297, 2012.

BARBOSA, H. R.; ASCHERI, R. P. R.; ASCHERI, J. L. R.; CARVALHO, C. W. P. Permeabilidade, estabilidade e funcionalidade de filmes biodegradáveis de amido de caroço de jaca (Artocarpus heterophyllus). Revista Agrotecnologia, v.2, p.73-88, 2011.

DAVANÇO, T.; TANADA-PALMU, P.; GROSSO, C. Filmes compostos de gelatina, triacetina, ácido esteárico ou capróico: efeito do $\mathrm{pH}$ e da adição de surfactantes sobre a funcionalidade dos filmes. Ciência e Tecnologia de Alimentos, v. 27, n.2, p. 408-416, 2007.

DU, W.-X., OlSEN, C. W., AVENA-BUSTIllOS, R. J., FRIEDMAN, M.; MCHUGH, T. H. Physical and antibacterial properties of edible films formulated with apple skin polyphenols. Journal of Food Science, v. 76, n. 2, p. 149-155, 2011. 
FARIAS, M.G.; FAKHOURI, F.M.; CARVALHO, C.W.P.; ASCHERI, J.L.R. Caracterização físico-química de filmes comestíveis de amido adicionado de acerola (Malphigia emarginata D.C.). Química Nova, v. 35, n.3, p. 546-552, 2012.

FERREIRA, M S. L.; SANTOS, M C. P; MORO, T.M. A.; BASTO, G J.; ANDRADE, R M. S.; GONÇALVES, E C. B. A. Formulation and characterization of functional foods based on fruit and vegetable residue flour. Journal of Food Science and Technology, DOI: 10.1007/s13197-013-10614, 2013.

FRANCHETTI, S.M.M.; MARCONATO, J.C. Polímeros biodegradáveis: uma solução parcial para diminuir a quantidade dos resíduos plásticos. Química Nova, v.29, n.4, p. 811-816, 2006.

GORNI, A.A. Aproveitamento de plástico pós-consumo na forma de combustível para altos-fornos e coquerias. Revista Plástico Industrial, v. 8, n. 89, p. 84-100, jan. 2006.

GUILBERT, S., GONTARD, N. Agro-polymers for edible and biodegradable films: review of agricultural polymeric material, physical and mechanical characteristics, in: Han, J.H. (Ed.), Innovations in food packaging. Elsevier Academic, pp. 263-276, 2005.

INNOCENTNI-MEI, L.H.; MARIANI, P.D.S.C. Visão geral sobre polímeros ou plásticos ambientalmente degradáveis PADs. Campinas: Editora Unicamp, 2005.

MARTELLI, M.R.; BARROS, T.T.; ASSIS, O.B.G. Filmes de polpa de banana produzidos por batelada: propriedades mecânicas e coloração. Polímeros, v. 24, n. 1, p. 137-142, 2014.

MARTELLI, M.; MOURA, M. R.; BARROS, T. T.; ASSIS, O.B.G. Edible films based on overripe bananas, pectin and chitosan nanoparticles. In: X Brazilian MRS Meeting, 2011, Gramado. X Brazilian MRS Meeting, 2011.

OOI, Z.X.; ISMAIL, H.; BAKAR, A.A., AZIZ, N. A. A. Properties of the Crosslinked Plasticized Biodegradable Poly(vinyl alcohol)/Rambutan Skin Waste Flour Blends. Journal of Applied Polymer Science, v. 125, p.1127-1135, 2012.

PARK, S.; ZHAO, Y. Development and characterization of edible films from cranberry pomace extracts. Journal of Food Science, v.71, p. 95-101, 2006.

PELIZER, L.H.; PONTIERI, M. H.; MORAES, I. O. Utilização de Resíduos Agroindustriais em Processos Biotecnológicos como Perspectiva de Redução do Impacto Ambiental. Journal of Technology Management \& Innovation, v.2 p. 118-127, 2007.

RODRIGUES, D.C. (2012). Influência de amido de mandioca e cera de carnaúba sobre as propriedades físicas de filme à base de goma de cajueiro. 2012. 90p. Dissertação (Mestrado em em Engenharia Química) - Universidade Federal do Ceará.

ROJAS-GRAU, M. A.; AVENA-BUSTILLOS, R.J.; FRIEDMAN, M.; HENIKA, P. R.; MARTINBELLOSO, O. MCHUGH, T.H. Mechanical, barrier, and antimicrobial properties of apple puree edible films containing plant essential oils. Journal of Agricultural and Food Chemistry, v. 54, n.24, p. 9262-9267, 2006.

SOUZA, C.O.; SILVA, L.T.; DRUZIAN, J.I. Estudo comparativo da caracterização de filmes biodegradáveis de amido de mandioca contendo polpas de manga e de acerola. Química Nova, v. 35, n. 2, p. 262-267, 2012.

ZAVAREZE, E.R.; HALAL, S.L.M.; TELLES, A.C. PRENTICE-HERNÁNDEZ, C. Biodegradable films based on myofibrillar proteins of fish. Brazilian Journal of Food Technology, IV SSA, p. 53-57, 2012. 